\title{
Effect of Silver Particles Electrodeposited on Reticulated Vitreous Carbon for Nitrate Reduction
}

\author{
S. S. Oishi ${ }^{\mathrm{a}}$, A. B. Couto ${ }^{\mathrm{a}}$, E. C. Botelho ${ }^{\mathrm{b}}$, and N. G. Ferreira ${ }^{\mathrm{a}}$ \\ ${ }^{a}$ LAS, Instituto Nacional de Pesquisas Espaciais, São José dos Campos, São Paulo \\ 12227-010, Brazil \\ ${ }^{\mathrm{b}}$ Department of Materials and Technology, UNESP-Univ Estadual Paulista, \\ Guaratinguetá, São Paulo 12516-410, Brazil
}

The electrocatalytic activity of silver particles electrodeposited on reticulated vitreous carbon (RVC) was evaluated for nitrate reduction. Different morphologies of silver deposits were obtained by varying the deposition potential, $\mathrm{AgNO}_{3}$ concentration solution, and deposition time. Silver deposit was not uniform due to the three-dimensional shaped electrode. The more elevated regions on the surface present a more intense deposition. The lowest silver ion concentration of $5 \mathrm{mM}$ associated to the lowest deposition time of $10 \mathrm{~s}$ provided the most uniform Ag deposition. The electrocatalytic activities for nitrate reduction were improved for electrodes with $\mathrm{Ag}$ deposited at potential of $-0.3 \mathrm{~V}$, time of $60 \mathrm{~s}$ and silver ion concentrations of 10 and $20 \mathrm{mM}$, probably due to the connection between Ag dendrites and Ag nanoparticles that increased the electrode surface area.

\section{Introduction}

Nitrate is a serious contaminant of ground and surface water mainly due to extensive use of fertilizers and improper industrial wastewater treatment, which cause high concern in the field of health and environmental protection $(1,2)$. Many processes have been used for nitrate removal and the electrochemical treatment is one of the most efficient due to its advantages regarding low cost effectiveness and ability to treat highly concentrated nitrate effluents (3). The electrode material is an important variable for the nitrate electroreduction process and the development of new electrodes to improve their catalytic activity is a challenge (4). The use of reticulated vitreous carbon as working electrode has shown some advantages such as good conductivity, high surface area, chemical stability and low cost (5). Cooper and silver electrodes present good activity for the electroreduction of nitrate (4), therefore the deposition of these metals onto carbon electrodes to enhance the catalytic activity have been tested with good results $(6,7,8)$.

There are few works on the literature exploring the use of three-dimensional electrode decorated with metals, therefore, in this work, the reticulated vitreous carbon (RVC) was used as support for silver electrodeposition and the effect of different parameters (applied potential, $\mathrm{AgNO}_{3}$ concentration and deposition time) on the morphology and electrocatalytic activity for nitrate reduction was studied. A correlation between silver particles morphology and electrochemical response for nitrate reduction was possible. 


\section{Experimental}

RVC was processed from the pyrolysis of poly(furfuryl alcohol) (PFA) resin synthesized by acid polycondensation of furfuryl alcohol. In a three-necked flask, $600 \mathrm{~mL}$ of furfuryl alcohol and $85 \mathrm{~mL}$ of diluted sulfuric acid $(0.5 \mathrm{M})$ were heated until $32{ }^{\circ} \mathrm{C}$ under magnetic stirring. Due to the exothermic reaction, the temperature increased without extra heating, and then the reaction was controlled to not exceed the temperature of $100{ }^{\circ} \mathrm{C}$ by cooling the water bath. After about $1 \mathrm{~h}$, the reaction was stopped and the PFA resin was distilled in a rotary evaporator until moisture at around $2 \%$. Polyurethane foams with 70 pores per inch were used as matrix for the anchorage of PFA catalyzed with 3 $w t \%$ of diluted p-toluenesulfonic acid $(60 \mathrm{wt} \%)$. The impregnated foams were cured and heat treat at $1000{ }^{\circ} \mathrm{C}$. The RVC foams were cut in disk shape with $20 \mathrm{~mm}$ diameter and $4.5 \mathrm{~mm}$ thickness.

Silver particles were electrodeposited under potentiostatic mode at $0.1,-0.3$ and -0.7 $\mathrm{V}$ vs $\mathrm{Ag} / \mathrm{AgCl}$ that can be related respectively to the onset of $\mathrm{Ag}$ deposition, massive deposition and diffusion controlled deposition. The $\mathrm{AgNO}_{3}$ concentrations solutions used were 5,10 and $20 \mathrm{mM}$ in $0.1 \mathrm{M} \mathrm{KNO}_{3}$ and the deposition times applied were 10, 60 and $180 \mathrm{~s}$. All electrochemical experiments were performed in a conventional three electrode cell using the RVC with electrodeposited Ag as working electrode, a Pt screen and $\mathrm{Ag} / \mathrm{AgCl}$ as the counter and reference electrodes, respectively. Electrocatalytic activity of the $\mathrm{Ag} / \mathrm{RVC}$ electrodes for nitrate reduction was performed by cyclic voltammetry in 0.1 $\mathrm{M} \mathrm{K}_{2} \mathrm{SO}_{4}$ solution containing $0.01 \mathrm{M} \mathrm{KNO}_{3}$. All the electrochemical experiments were accomplished after deaerating the solution with $\mathrm{N}_{2}$ gas for $10 \mathrm{~min}$. The morphology of the samples was evaluated by field emission gun scanning electron microscopy (FEGSEM) using a Tescan Mira3 at an accelerating voltage of $20 \mathrm{kV}$.

\section{Results and Discussion}

Figure 1 shows the morphologies obtained from Ag deposits on RVC at $0.1,-0.3$ and -0.7 $\mathrm{V}$ vs $\mathrm{Ag} / \mathrm{AgCl}$ (named $\mathrm{RVC} 1, \mathrm{RVC} 2$ and $\mathrm{RVC} 3$, respectively). Due to the threedimensional morphology, silver deposition is not uniform as can be observed in Figure 1 a,b,c. The most elevated regions closest to the anode receive a more intense deposition due to the decrease of diffusional region on the electrode/electrolyte interface. On the other hand, deeper electrode regions present smaller aggregates of Ag particles. When the deposition potential $0.1 \mathrm{~V}$ vs $\mathrm{Ag} / \mathrm{AgCl}$ is used (Figure $1 \mathrm{~b}$ ), the formation of discrete silver aggregates of around $2 \mu \mathrm{m}$ is predominantly observed. At potential of $-0.3 \mathrm{~V}$ (Figure 1d), a mixture of particles and interconnected branchlike structures is formed, in addition to small nanoparticles covering all the substrate. At the most negative potential of $-0.7 \mathrm{~V}$ (Figure 1f), dendritic structures at about $5 \mu \mathrm{m}$ are predominantly obtained.

The Ag/RVC electrodes obtained from different deposition potentials were evaluated for nitrate reduction by cyclic voltammetry as shown in Figure 2. There is no response of nitrate for the bare RVC since its voltammogram in blank solution (not shown) is similar to that in the nitrate presence. In all cases, the catalytic activity of silver particles for nitrate reduction is realized by the positive shifting of the onset potential and an increase in the cathodic current. RVC2 sample shows a more positive onset potential and higher cathodic current in comparison to those of RVC1 and RVC3, which means that the morphology obtained in these samples facilitate the nitrate reduction. Moreover, the 
interconnected branchlike structure and the presence of $\mathrm{Ag}$ nanoparticles on $\mathrm{RVC} 2$ probably resulted in a larger surface area.

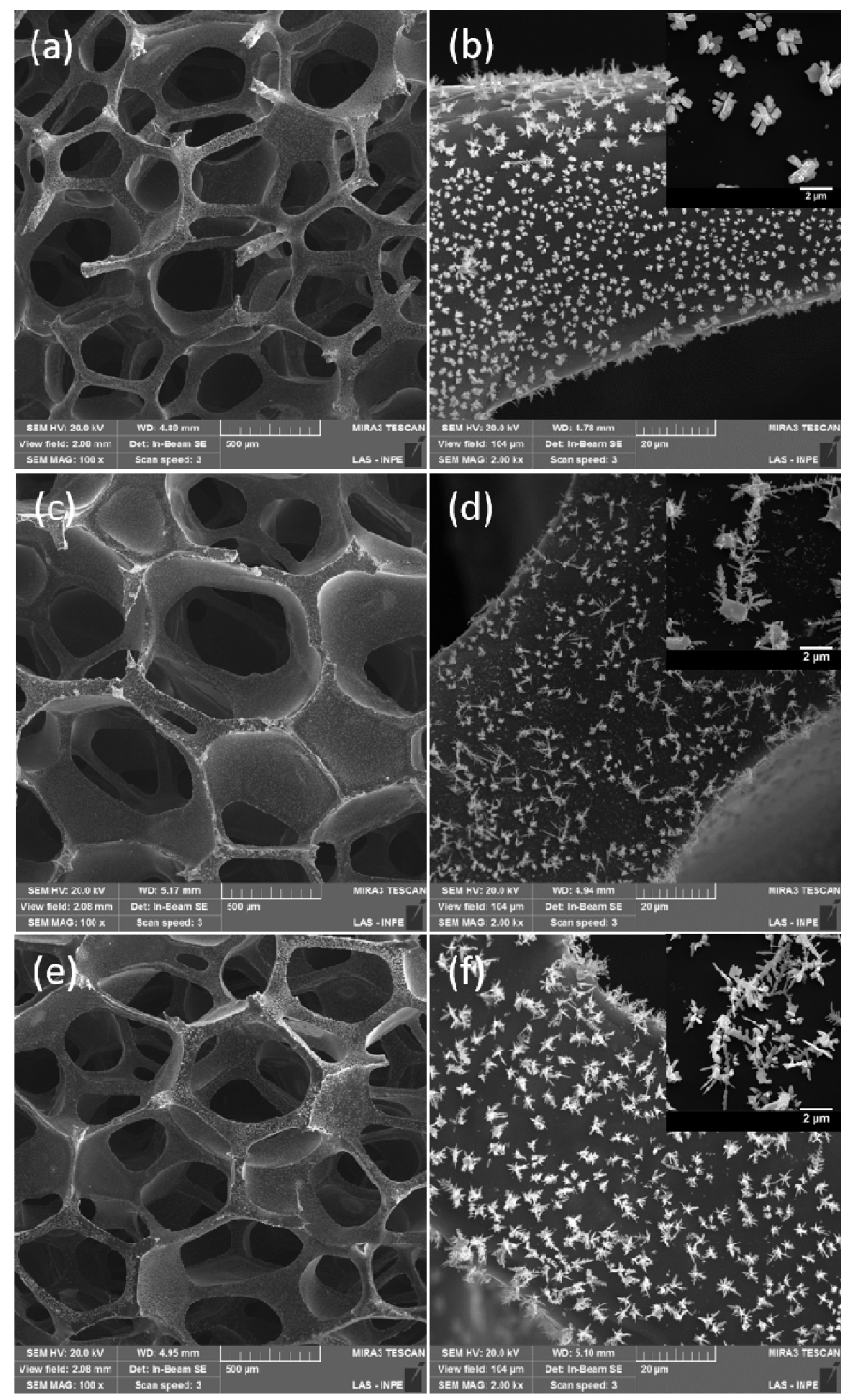

Figure 1. SEM images of Ag deposits on RVC at different potentials: (a, b) $0.1 \mathrm{~V},(\mathrm{c}, \mathrm{d})$ $0.3 \mathrm{~V}$, (e, f) $-0.7 \mathrm{~V}$ vs $\mathrm{Ag} / \mathrm{AgCl}$. Deposition time of $60 \mathrm{~s}$ and $\mathrm{AgNO}_{3}$ solution of $10 \mathrm{mM}$. 


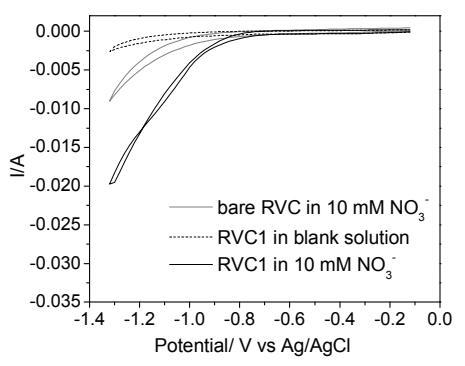

(a)

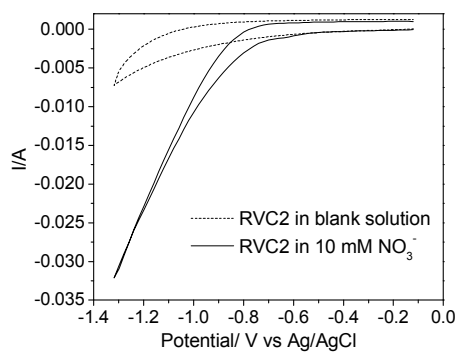

(b)

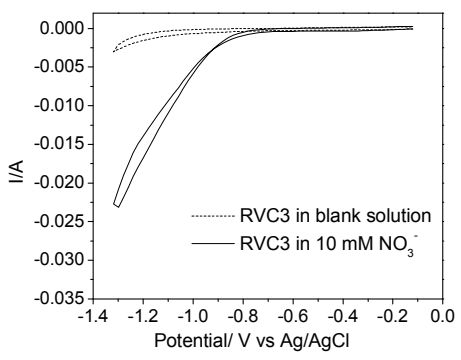

(c)

Figure 2. Cyclic voltammograms of: (a) bare RVC and RVC1, (b) RVC2 and (c) RVC3 in $0.1 \mathrm{M} \mathrm{K}_{2} \mathrm{SO}_{4}$ (dashed line) and $0.01 \mathrm{M} \mathrm{KNO}_{3}+0.1 \mathrm{M} \mathrm{K}_{2} \mathrm{SO}_{4}$ (solid line).

Figure 3 presents the SEM images of samples in which $5 \mathrm{mM}$ and $20 \mathrm{mM}$ concentrations of silver nitrate solution (named RVC4 and RVC5, respectively) were used for $\mathrm{Ag}$ deposition. In this case, the best potential response for nitrate reduction established previously of $-0.3 \mathrm{~V}$ and fixed time of $60 \mathrm{~s}$ were applied. RVC4 sample (Figure 3a) obtained at lower silver ion concentration exhibits a more uniform deposition with silver agglomerates of about $1 \mu \mathrm{m}$ (Figures $3 \mathrm{~b}$ ). It is also possible to observe dispersed Ag nanoparticles covering all the substrate. RVC5 sample shows some elevated areas with dense concentration of dendritic structures (Figure 3c). Though, most of RVC5 sample is highly covered with silver aggregates and small particles as shown in Figure $3 \mathrm{~d}$. The response for nitrate reduction of RVC4 and RVC5 samples are presented in Figure $4 \mathrm{a}$ and $4 \mathrm{~b}$, respectively. It is evident the catalytic activity increase with increasing silver ion concentration solution due to the cathodic current increment. For RVC5 sample, the separation of nitrate reduction process and hydrogen evolution reaction (HER) can be observed by a slight shoulder at about $-0.8 \mathrm{~V}$, indicating the nitrate reduction to nitrite.

Besides the electrodeposition potential and silver ion concentration, different deposition times were also studied keeping the potential at $-0.3 \mathrm{~V}$ and silver concentration solution of $20 \mathrm{mM}$ as shown in Figure 5. The morphology obtained at low magnification with deposition time of $10 \mathrm{~s}$ (Figure 5a, named RVC6 sample) also presents a uniform deposition without large clusters on RVC surface. At higher magnification of RVC6 sample (Figure 5b), one can observe small dendrites and Ag aggregates at around $2 \mu \mathrm{m}$. On the other hand, deposition time of $180 \mathrm{~s}$ (Figure 5c,d, named RVC7 sample) generates regions with large agglomeration of dendritic structures, which were partially removed after rinsing with water. Although larger amount of silver on RVC7 presented a good catalytic activity (Figure 6b), this condition is not reproducible, not to mention the lower cathodic current obtained when compared to that of the RVC5 electrode. It is worth mentioning that larger size of Ag aggregates obtained for RVC6 sample was not effective to improve its catalytic activity (Figure 6a), since only a slight variation in the reductive current in the nitrate presence was observed. 


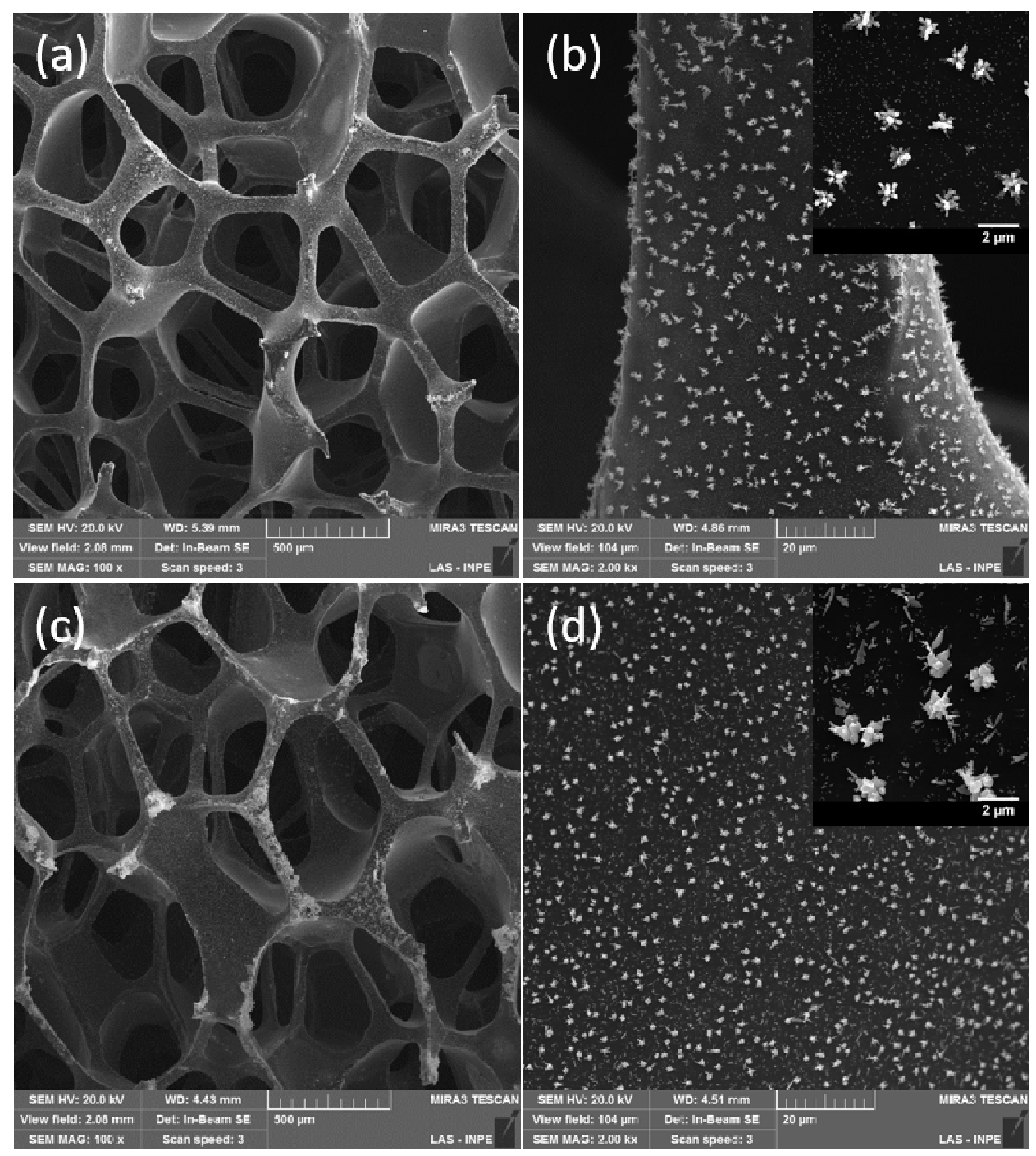

Figure 3. SEM images of Ag deposits on RVC at different silver concentration solution: (a, b) $5 \mathrm{mM}$ and (c, d) $20 \mathrm{mM}$. Deposition time of $60 \mathrm{~s}$ at $-0.3 \mathrm{~V}$ vs $\mathrm{Ag} / \mathrm{AgCl}$.

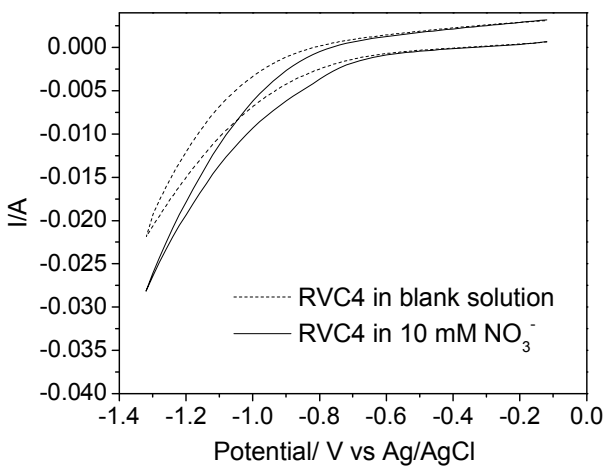

(a)

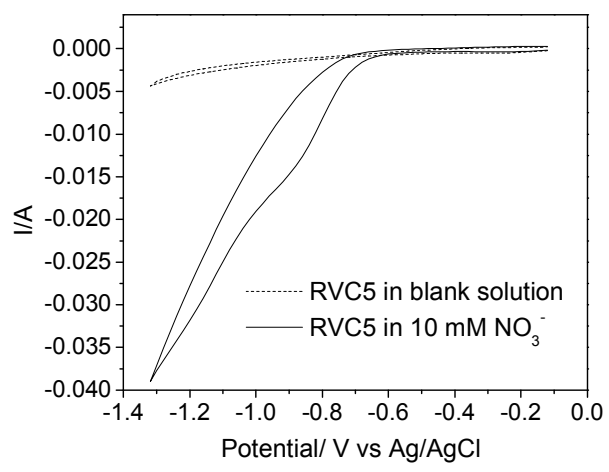

(b)

Figure 4. Cyclic voltammograms of: (a) RVC4 and (c) RVC5 in $0.1 \mathrm{M} \mathrm{K}_{2} \mathrm{SO}_{4}$ (dashed line) and $0.01 \mathrm{M} \mathrm{KNO}_{3}+0.1 \mathrm{M} \mathrm{K}_{2} \mathrm{SO}_{4}$ (solid line). 


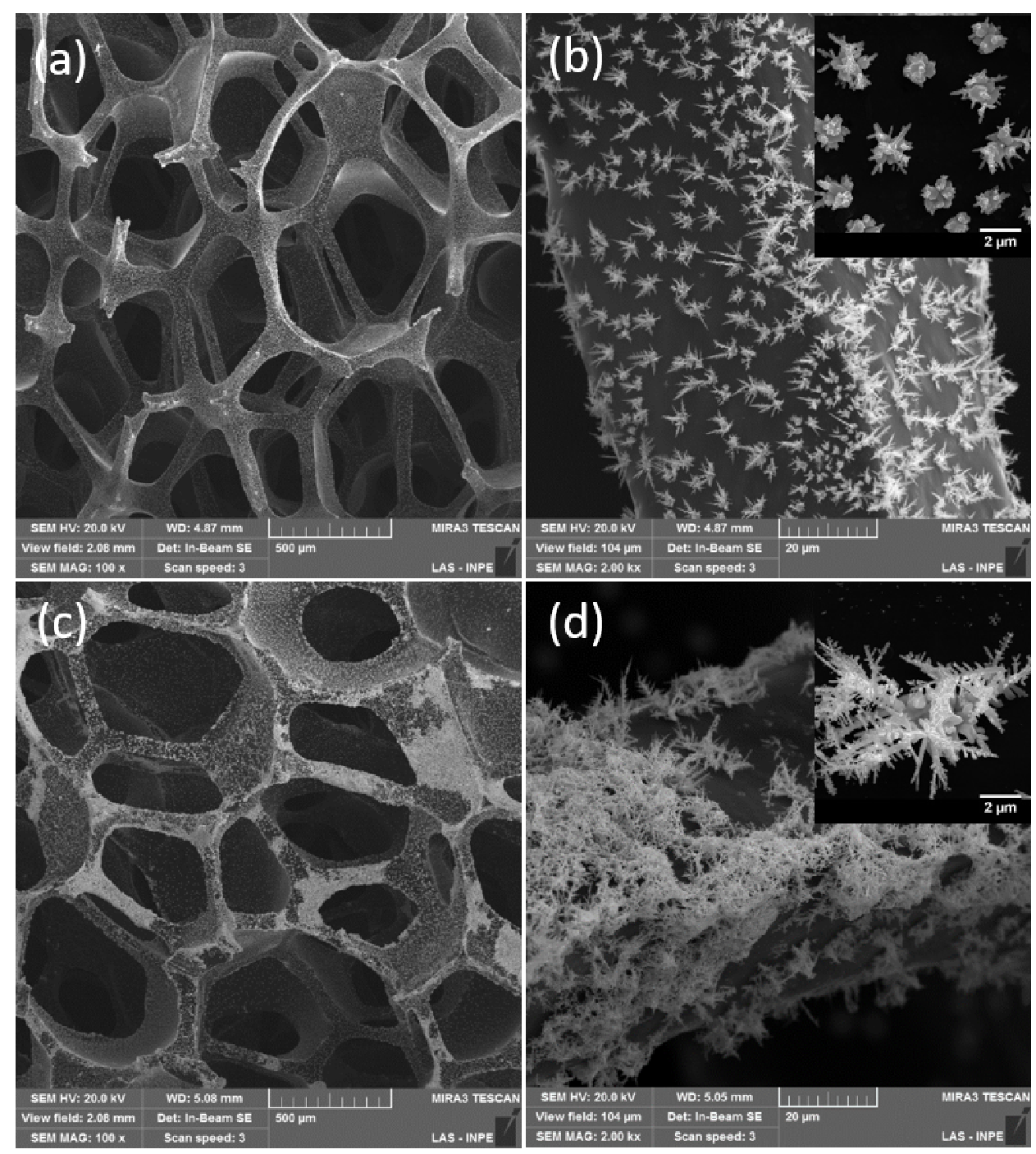

Figure 5. SEM images of Ag deposits on RVC at different deposition times: $(\mathrm{a}, \mathrm{b}) 10 \mathrm{~s}$ and (c, d) $180 \mathrm{~s} . \mathrm{AgNO}_{3}$ solution of $20 \mathrm{mM}$ at potential of $-0.3 \mathrm{~V}$ vs $\mathrm{Ag} / \mathrm{AgCl}$.

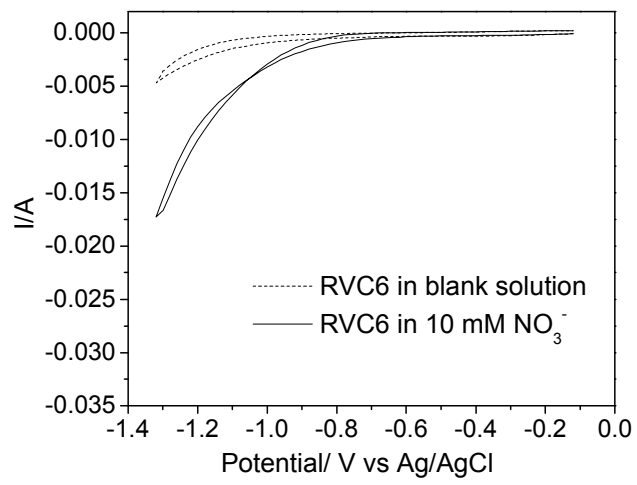

(a)

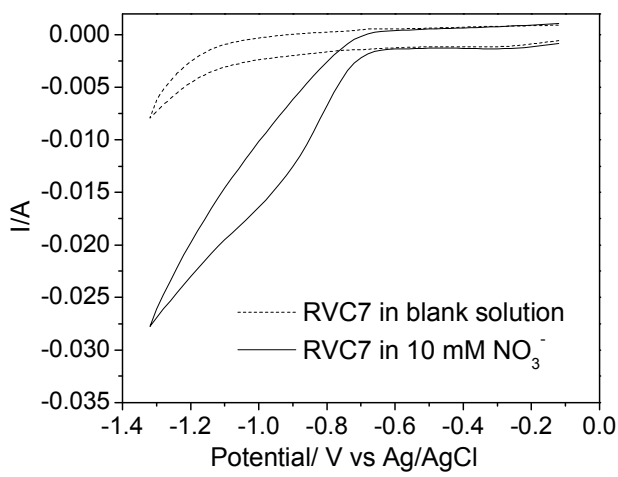

(b)

Figure 6. Cyclic voltammograms of: (a) RVC6 and (c) RVC7 in $0.1 \mathrm{M} \mathrm{K}_{2} \mathrm{SO}_{4}$ (dashed line) and $0.01 \mathrm{M} \mathrm{KNO}_{3}+0.1 \mathrm{M} \mathrm{K}_{2} \mathrm{SO}_{4}$ (solid line). 
Table I shows the mass of deposited Ag calculated by using Faraday's law and the onset reduction potential in the presence of nitrate. The mass values of Ag deposits are almost similar for deposition potentials of 0.1 and $-0.3 \mathrm{~V}$ (1.14 and $1.15 \mathrm{mg}$, respectively) and present an increase for potential of $-0.7 \mathrm{~V}(1.53 \mathrm{mg})$. A substantial increase in the mass of Ag deposits is observed when the highest concentration of silver ion solution (20 $\mathrm{mM})(3.12 \mathrm{mg})$ and at the highest deposition time of $180 \mathrm{~s}(6.46 \mathrm{mg})$. An enhanced onset reduction potential for samples RVC2 and RVC5 in comparison to those of RVC1 and RVC4 samples can be related to the connection between Ag dendrites and nanoparticles that increase the sample surface area. An increase in the Ag deposited sizes do not improve the onset reduction potential as can be observed for RVC3 and RVC6, respectively. Although Ag particles present good anchorage on carbon substrate, a large amount of Ag deposit on RVC surface was not supported and loss of silver was observed for RVC7 sample, which hinders the reproducibility of the result.

TABLE I. Mass of Ag deposited on RVC electrodes and the onset reduction potential.

\begin{tabular}{ccc}
\hline Sample & Mass of Ag deposited (mg) & Onset reduction potential (V) \\
\hline RVC1 & 1.14 & -0.70 \\
RVC2 & 1.15 & -0.60 \\
RVC3 & 1.53 & -0.70 \\
RVC4 & 0.52 & -0.70 \\
RVC5 & 3.12 & -0.64 \\
RVC6 & 0.82 & -0.74 \\
RVC7 & 6.46 & -0.66 \\
\hline
\end{tabular}

\section{Conclusion}

Ag deposition on RVC was obtained with different morphologies depending on the employed experimental condition. The electrocatalytic activity of electrodeposited silver particles for nitrate reduction was observed in all conditions in comparison to a bare RVC electrode. Larger and well dispersed Ag particles resulted in lower response for nitrate reduction while the presence of interconnected dendrites and Ag nanoparticles presented the best electrocatalytic activity. This behavior was associated to the electrode surface area increase. Regarding these results, the Ag electrodeposition can be controlled by using different experimental conditions as well as their mass and morphology that are crucial to enhance the catalytic activity for nitrate reduction.

\section{Acknowledgments}

The authors acknowledge the financial support from São Paulo Research Foundation (FAPESP) grant \#2014/27164-6 and CAPES.

\section{References}

1. J.W. Peel, K.J. Reddy, B.P. Sullivan, and J.M. Bowen, Water Res., 37, 2512 (2003). 
2. M. Li, C. Feng, Z. Zhang, S. Yang, and N. Sugiura, Bioresour. Technol., 101, $6553(2010)$.

3. A. S. Koparal and Ü.B. Ö̈tveren, J. Hazard. Mater., 89, 83 (2002).

4. Y. Feng, L. Yang, J. Liu, and B.E. Logan, Environ. Sci. Water Res. Technol., 2, 800 (2016).

5. F.C. Walsh, L.F. Arenas, C.P. de León, G.W. Reade, I. Whyte, and B.G. Mellor, Electrochim. Acta, 215, 566 (2016).

6. I.G. Casella and M. Ritorti, Electrochim. Acta, 55, 6462 (2010).

7. L. Guadagnini and D. Tonelli, Sensors Actuators, B Chem., 188, 806 (2013).

8. A.B. Couto, S.S. Oishi, and N.G. Ferreira, J. Ind. Eng. Chem., 39, 210 (2016). 